\title{
Steak tournedos or beef Wellington: an attempt to understand the meaning of Stone Age transformative techniques
}

\author{
Patrick Schmidt (iD) $1,2 \bowtie$
}

Research into human uniqueness is gaining increasing importance in prehistoric archaeology. The most striking behaviour unique to early and modern humans among other primates is perhaps that they used fire to transform the properties of materials. In Archaeology, these processes are sometimes termed "engineering" or "transformative techniques" because they aim at producing materials with altered properties. Were such transformative techniques cognitively more demanding than other tool making processes? Were they the key factors that separated early humans, such as Neanderthals and early Homo sapiens, from other hominins? Many approaches to investigating these techniques rely on their complexity. The rationale behind this is that some techniques required more steps than others, thus revealing the underlying mechanisms of human uniqueness (e.g., unique human culture). However, it has been argued that the interpretation of process complexity may be prone to arbitrariness (i.e., different researchers have different notions of what is complex). Here I propose an alternative framework for interpreting transformative techniques. Three hypotheses are derived from an analogy with well-understood processes in modern-day cuisine. The hypotheses are about i) the requirement in time and/or raw materials of transformative techniques, ii) the difficulty to succeed in conducting transformative techniques and iii) the necessity to purposefully invent transformative techniques, as opposed to discovering them randomly. All three hypotheses make testable predictions.

\footnotetext{
${ }^{1}$ Department of Early Prehistory and Quaternary Ecology, Eberhard Karls University of Tübingen, Tübingen, Germany. ${ }^{2}$ Applied Mineralogy, Department of Geosciences, Eberhard Karls University of Tübingen, Tübingen, Germany. ${ }^{凶}$ email: patrick.schmidt@uni-tuebingen.de
} 


\section{Introduction}

$\mathrm{n}$ prehistoric archaeology, human uniqueness and the exact moment of its appearance in time are hotly debated topics.

The pre-2000s were marked by theories proposing a late onset of behavioural modernity (Noble and Davidson, 1991) that was thought to appear significantly later in human evolution than anatomical modernity (e.g., Klein, 1995; Mellars and Stringer, 1989; Bar-Yosef, 1998). This model has been refuted since (e.g., McBrearty and Brooks, 2000), by showing that the advent of modernity rather was a slow and gradual process across the entire African Middle Stone Age (300-30 ka). What all of these models have in common is their definition of behavioural modernity: the presence of specific artefact categories (often-called traits) in the archaeological recorded. Such traits may be objects documenting symbolic behaviours, such as personal ornaments or engraved objects (e.g., Henshilwood et al., 2009; d'Errico et al., 2005), elaborate stone tools (McBrearty and Brooks, 2000), or compound tools assembled from several materials such as barbed points (e.g., Wadley, 2010a). More recently, the concept of behavioural modernity has been criticised for its inconsistency throughout the archaeological record of Homo sapiens (e.g., Petraglia et al., 2010; Lombard and Parsons, 2011), methodological issues (e.g., Shea, 2011) or its inability to distinguish between different hominins (e.g., D’Errico, 2003; Zilhão, 2007). Several alternative concepts that may explain human uniqueness have been proposed, such as behavioural variability (Shea, 2011), metaplasticity (Malafouris, 2010) or complex cognition (Wadley, 2013). These theories offer alternative ways to interpret objects, behaviours or types of artefacts in their respective theoretical framework (for example, mixing plant gum with ochre to make adhesives requires multi-tasking and abstract thought, as in: Wadley, 2010b). What these approaches do not provide is a quantitative means of comparing different behaviours, i.e., it cannot be measured, which behaviours are of greater relevance for identifying human uniqueness and which of lesser. This paper attempts to identify such a quantitative approach to understanding Stone Age techniques.

What are transformative techniques and early engineering? The material leftovers of ancient people may be the result of two apparently different types of behaviours. In Stone Age archaeology, most of the known artefacts were made by transforming the shape of raw materials to obtain new properties (e.g., knapping a cutting edge on a stone tool; forming a tipped bone tool by grinding; drilling a hole in a shell bead). The immediately visible change in morphology is understood to be the consequence of the action. Production methods can be learned by other individuals by observation (Bandura, 1997). There is an ongoing debate (e.g., Tennie et al., 2016; Haidle and Schlaudt, 2020; Whiten, 2011) on whether all of these techniques require a process of cultural transmission to be learned by naïve individuals, some (Tennie et al., 2017) even suggesting that some techniques may have been regularly reinvented instead of transmitted culturally. In this case, many of the earliest artefacts would contain no information about the processes of cultural transmission per se. What is certain is that such active shape transformations were the first manifestations of the human lineage's tool making behaviour from 3.3 Ma on and throughout all of the Early Stone Age (Harmand et al., 2015; Semaw et al., 2003). Another type of Stone Age artefacts results from human actions that do not involve immediately visible transformations of the shapes of objects. Examples of such activities are heat treatment of stone to improve its quality for tool knapping (e.g., Stolarczyk and Schmidt, 2018); reddening of yellow ochre with fire (e.g., Wadley, 2013); and the distillation of plant exudations to produce glues (e.g., Groom et al., 2015). Either these processes result in new materials that behave differently or they create new substances that did not exist in nature before the transformation process. Such activities are sometimes referred to as the first manifestations of material engineering (as in Brown et al., 2009) or transformative techniques (as in Wadley, 2013) because they involve the transformation of material properties (colour, fracture behaviour, etc.) instead of shape. Some of these transformative techniques have been interpreted as procedures that cannot be observed or controlled during the process (Stolarczyk and Schmidt, 2018). Such transformative processes rely on the use of fire, pinpointing a behaviour that is fundamentally different from that of other non-human hominids.

The first such procedure used by Homo sapiens to intentionally alter the physical properties of materials was heat treatment of stone (Brown et al., 2009). In Africa, it became a regular component of tool making before $125 \mathrm{ka}$ (Schmidt et al., 2020) and it remained present throughout the archaeological record till the Holocene (see for ex: Delagnes et al., 2016; Porraz et al., 2016). In Australia, the first colonists began to heat-treat silcrete as soon as they arrived on the continent (Schmidt and Hiscock, 2020a; Schmidt and Hiscock, 2020b). Heat treatment was also part of the suite of innovations associated with the Upper Palaeolithic Solutrean culture (25.5-23 ka BP) in Europe (Bordes, 1969; Aubry et al., 2008) and the Siberian Dyuktai culture ( $\sim 18 \mathrm{ka} \mathrm{BP,} \mathrm{Flenniken,} \mathrm{1987).} \mathrm{While} \mathrm{in} \mathrm{Africa,} \mathrm{the}$ technique used for stone heat treatment has been studied in detail (e.g., Schmidt et al., 2015; Delagnes et al., 2016; Schmidt et al., 2016a), heating techniques remain totally unknown for the early archaeological record of Australia and only fragmentary data are available for the European Solutrean (Schmidt and Morala, 2018; Schmidt and Morala, 2020). The implications of this lack of data about the larger part of Stone Age heat treatment in the world are that we cannot understand the meaning of heat treatment for human cultural evolution, the diffusion of ideas or the dynamics of invention. For example, some authors (Wadley and Prinsloo, 2014) argue that stone heat treatment in an oven-like structure underground required analogical reasoning and complex cognition. Others (Brown and Marean, 2010; Schmidt et al., 2016b) highlight the need of large amounts of resources and time for such underground processes. Only new data may allow understanding whether these concepts are also applicable to heat treatment in different contexts. Another Stone Age transformative technique is the intentional transformation of pigments to obtain colourants with staining properties not available in nature. The earliest examples of such ochre reddening are documented in South Africa, where they occur from $\sim 100 \mathrm{ka}$ on (Dayet et al., 2013; Dayet et al., 2017; Wojcieszak et al., 2017). These early dates, which fall in a period of significantly increasing ochre use in general (Hodgskiss, 2020), suggest an important role of reddened ochre in symbolic behaviours. The concomitant use of stone and ochre heat treatment in the later part of the Middle Stone Age (MSA) raises interesting questions about their association and interdependence. For example, some authors (e.g., Wadley, 2013) propose that if ochre heat treatment relied on underground processes, similar to those proposed for stone heat treatment in some contexts, it might be another proxy for complex cognition in the MSA. Outside of Africa, the earliest secure evidence of colour enhancement dates to $100 \mathrm{ka}$ in Israel (Salomon et al., 2012; Godfrey-Smith and Ilani, 2004). In the European Upper Palaeolithic, ochre heat treatment is documented in Italy (Cavallo et al., 2018) and France (Salomon et al., 2013; Salomon et al., 2015). The third often cited transformative technique is the production of glues from plant exudations. Glue making also requires the idea to transform naturally available resources to produce entirely new substances. The earliest manufactured glues date to $\sim 200 \mathrm{ka}$ in Italy and are attributed to Neanderthals (Mazza et al., 2006). A few other tar finds are known from The Netherlands (Niekus et al., 2019) and 
Germany (Pawlik and Thissen, 2011; Grünberg et al., 1999). These artefacts are of importance for understanding the culture and capabilities of Neanderthals because they are made of birch tar. To make birch tar, the bark of the birch tree must be heated so that an adhesive is formed by distillation. This means that there is no visible precursor phase (such as resin) that could have been observed, or that could have provided information about the potential to make an adhesive substance from the bark (Koller et al., 2001). Several sites in Italy (Degano et al., 2019) and North Africa (Rots et al., 2011) have yielded traces of resinous residues on stone tools. In southern Africa, several MSA and Late Stone Age (LSA) sites produced large numbers of adhesive remains that date back to $\sim 100$ ka (Wadley, 2010b; Lombard, 2007; Charrié-Duhaut et al., 2013). The production processes of Stone Age birch tar and other adhesives derived from plant resins remain totally unknown today.

Thus, transformative techniques appear after $200 \mathrm{ka}$ in Neanderthals and around $100 \mathrm{ka}$ in Homo sapiens. These dates correlate neither with the appearance of these species, nor with their arrival in their respective environments. They might translate important developments or turning points in human evolution.

Several research questions result from these observations: What do early transformative processes tell us about the technology of ancient people and do they imply sophisticated cognition or social learning processes? Does the mastering of such processes entail a different set of cognitive abilities than other processes? How can transformative technologies be invented when processes cannot directly be observed? The main impediment for answering these questions is that most of the steps involved in such transformative processes remain unknown for almost all techniques and in almost all contexts. The meaning of transformative techniques for our understanding of the cultural evolution of early humans therefore remains unclear today.

The aim of this paper is not to introduce archaeological or experimental data on transformative processes, rather to provide a framework in which such data can be interpreted. For this, I propose an approach to the formulation of hypotheses, based on an analogy with well-understood processes involved in modern-day cooking: the steak vs. beef Wellington parallel. In a second step, I will evaluate whether some of the differences identified on the bases of this analogy may be applicable to Stone Age transformative techniques. Those that are, will be used to formulate predictions that can be tested by archaeological and experimental investigation.

\section{An analogy with modern-day cooking}

To draw an analogy, we will empathise with a chef, working in a restaurant, who prepares two different dishes. For that matter, our cook will prepare two meat-based dishes. One of the difficulties associated with this, is to achieve a precise degree of doneness (i.e., some customers like it well done, some rare, etc.). In modern-day restaurants, this may be done with meat thermometers but, for the sake of argument, we will suppose that there are no thermometers in this restaurant. Thus, our cook has a limited number of options, the choice of which depends on the piece of meat to be prepared.

Consider the cooking process necessary for preparing a steak, say a tournedos cut from the beef tenderloin. A tournedos is best prepared by searing it in a skillet, a process during which it can be monitored by the cook along the cooking process. This means that doneness can be tested for during the process using a hand test. The steak is rare if it feels (to the touch) like the soft fleshy part of the chefs palm between his thumb and wrist, when his thumb and forefinger touch. The steak is medium when it feels like the chef's palm when his thumb and middle finger are joined, etc. Once the steak reaches the desired degree of doneness, the cooking process is stopped. Our chef must previously have acquired a certain level of skill to conduct this hand test but, generally, the test is straightforward because it can be repeated several times during the process and the results can be compared. Thus, our chef has the possibility to compare the evolution of the tournedos at different moments of the cooking process.

Now, consider the case of a beef Wellington. In this recipe, a piece of the beef tenderloin is quickly seared on all sides and then enveloped in a duxelle (a paste made from mushrooms), thin strips of lard and an outer layer of puff pastry. This package is then cooked in an oven so that the pastry around it is baked and the meat inside is brought to the desired doneness at the same time. This means that the meat is cooked hidden from the chef s sight. The doneness can only virtually be assessed in the chefs mind who has no means of controlling for it throughout the process: i.e., hitting the moment the Wellington must be removed from the oven entirely depends on the chef s experience. The only way of achieving consistency in preparing such a dish is by following precise instructions. Either these may be the results of social learning (i.e., the chef studied at a cooking school) or they may result from a self-established referential based on previously made beef Wellingtons that either failed or succeeded.

From these explanations, it can be intuitively appreciated why preparing a beef Wellington many be considered as more difficult than searing a steak. But which are the measurable differences? The first obvious difference is that the overall complexities of both recipes are different. In this case, complexity may be understood as the total amount of steps needed to conduct the task (see for ex: Bettinger and Eerkens, 1997). At first glance, this appears to be useful because the preparation of the Wellington includes more steps than the tournedos. However, both recipes allow a certain degree of liberty with regard to the number of steps that are performed. For example, the steak tournedos may be seared on high flame in a skillet until it is done; alternatively, it might be transferred half-cooked to a preheated oven until it reaches doneness; or it might be finished under a salamander oven. Such supplementary steps are not strictly necessary but provide advantages for the workflow of our chef and are therefore common practice in modern-day cuisine. The point here is that a customer, who is eating a steak, cannot deduce how many steps the chef actually conducted to cook it. Thus, in our example, making statements about the number of steps performed by the chef, for either of the two dishes, is arbitrary from the point of view of the customer and it likely does not reflect reality.

The only way a customer can distinguish both recipes in terms of what happened in the kitchen, is by identifying proxies, in the steak or the Wellington, that he can link to specific processes of the cooking procedure. The observation of proxies in the finished dish allows for testing hypotheses that the customer formulated. For example, it seems to be possible to separate both dished based on the investment they require. A prediction would be: the Wellington requires more ingredients and a higher investment in total time. This prediction can be tested, even without knowledge of the cooking technique, because it is possible to i) count the observable ingredients (one proxy) and ii) gather experimental data on the requirements of meat to reach a given doneness in both conditions (i.e., a $2.5 \mathrm{~cm}$ thick tournedos vs. a $12 \times 20 \mathrm{~cm}$ piece of tenderloin wrapped in pastry; the doneness observed in the finished dish is the other proxy). The consequences of this prediction are importantin our example, they are: the total amount of used ingredients and the time invested by the chef would likely lead to the Wellington being higher priced on the restaurant's menu.

There also appears to be another way to distinguish both dishes based on testable criteria: by identifying the risk associated with their preparation. This directly translates into saying that one dish is more difficult than the other. In our example, the rationale behind this is that, only for the steak tournedos, our chef has the possibility 
to intervene in the cooking process, terminate it or change parameters. For the Wellington, every infidelity in executing the recipe may cause deviance from the projected outcome. A possible prediction therefore is: preparing steak tournedos results in a higher success rate than beef Wellington. This prediction can be tested by measuring success rate over a given time span in learners and expert chefs (perhaps by ordering the same dishes repeatedly or with the help of the disciples of a cooking school). The consequences of the prediction are that only chefs who have acquired a higher level of skill can prepare the beef Wellington.

There even seems to be one more level of difference between both dishes, which can only be understood if they are put in their historical context. It is unclear when exactly the technique of searing was invented in the history of humankind but it is likely rather old. What is certain is that the history of the beef Wellington is significantly shorter. Whether the often held believe that the dish was invented in celebration of the first Duke of Wellington's victory at Waterloo is true, or whether the dish predates 1815, being base on the continental filet de bouf en croute, cannot be decided here. What this historical perspective suggests, is that the beef Wellington is an evolution of other techniques that may have helped inventing it. Thus, the prediction is: the beef Wellington is the result of the combination of earlier cooking techniques. This prediction can be tested by gathering data on the phylogenetic relationship between traits (in this case components involved in the Wellington; searing, smoking and curing of lard, etc., in other word our customer has to become a historian of culinary arts, or at least contact one). If the hypothesis were confirmed, it would translate into saying that the Wellington can be considered as more evolved (i.e., it is a combination of several older concepts).

\section{Are these concepts applicable to the study of Stone Age transformative techniques?}

Following the three levels of difference established on the example of the steak tournedos and the beef Wellington, it might be possible to identify similar levels of difference for the archaeological study of transformative techniques.

[1] As for the first hypothesis described above, which stated that the Wellington is associated with greater cost than the steak, it appears that some techniques require more time and/or raw materials than others. Producing artefacts with these techniques is therefore associated with higher cost of one or more types. For example, cost-benefit relationships have previously been used for understanding fire making (e.g., Henry et al., 2018). This approach, based on the caloric expenditure necessary for firewood collection and its relation to the caloric advantage provided by fire (e.g., cooking), provide a quantitative understanding of the cost-benefit ratio of fire in archaeological contexts (Henry, 2017). Transformative techniques that are based on gathering different raw materials from potentially different geological and ecological frameworks may be investigated by similar methods. Other approaches address the cost-benefit relation of local vs. non-local raw materials. For example, some authors (e.g., Gould and Saggers, 1985) found that tool-stone quality justified supplementary investment in raw material procurement. This might also be applicable to the study of transformative techniques. Unfortunately, it is not straightforward to quantify the real benefits provided by most transformative technologies (e.g., Schmidt and Mackay, 2016). However, time and energy requirement, even without the understanding of benefit, may be a quantifiable criterion for distinguishing transformative techniques from other techniques. This is of course only if time and energy investment were to be found superior to other techniques. For example, transformative techniques that are based on indirect heating in underground oven-like structures (Kozowyk et al., 2017; Eriksen, 1997; Wadley, 2013) might document the willingness to invest large amounts of time and raw material. This is so because to conduct them one must invest energy in building underground structures, afford the raw materials and spend time waiting for the (generally slow) underground processes to take place. Consider an example: in stone heat treatment, the heating conditions (temperature and duration) attained in heat-treated artefacts can be reconstructed through the rocks' thermal transformations (for a possible methodology see: Schmidt et al., 2019b). Based on these data, it is possible to conduct an experimental programme to investigate the time and resources necessary to attain the degree of thermal transformation measured in artefacts. This was done for the time investment necessary to heat-treat two different raw materials, the silica rocks chert and silcrete (Schmidt et al., 2016b; Schmidt, 2014; Schmidt et al., 2013). The results showed that chert requires more than double the time to attain the perused thermal transformations than silcrete (compare: Schmidt et al., 2016b; Schmidt et al., 2017). These findings shed light on the minimum time requirement necessary to heat-treat both materials and allows for comparing the cost of two transformative techniques conducted in different archaeological contexts (namely contexts in which either chert or silcrete was heat-treated). The approach was based on physically measurable time requirements for achieving thermal transformations in materials (i.e., only the kinetics of the chemical transformations and measurable physical processes like heating and cooling rates were compared). It was not based on interpretations of the duration of possible sequences of actions performed during heat treatment (that are highly arbitrary). This approach bears potential for similar studies on other transformative techniques.

[2] Similar to the hypothesis that a Wellington may be more difficult to prepare than a steak, some Stone Age techniques also appear to include greater risk of failure than others. To increase expected likelihood of success when conducting high-risk techniques, specific processes-recipes-must be executed precisely. Lewis and Laland (2012) argued that high fidelity copying is one of the key elements for the built-up of cumulative culture. The idea was later questioned by Saldana et al. (2019) who argue that cumulative culture may also result from mechanisms based on low fidelity copying. The aim of this paper is not to take part in the fidelity debate (in the sense that is does or does not indicate cumulative culture), rather it is to try to identify testable ways of separating techniques based on the required know-how. This know-how may be better understood by Csibra and Gergely's (2011) concept of cognitively opaque skills, which describes mechanisms than cannot be understood by the person who executes them. Knowledge with opaque content must be transmitted via high fidelity copying, perhaps even requiring communicative knowledge transmission (Csibra and Gergely, 2011). Processes that take place hidden from sight in transformative techniques (underground for example) are likely to be cognitively opaque in this sense. The question then becomes, how can we investigate whether transformative techniques require special know-how and therefore cultural transmission such as high fidelity copying? One possibility might be by examining if a specific technique requires high fidelity execution of a recipe. And indeed, some primatologists have used success rates to infer degree of fidelity in copying (e.g., Canteloup et al., 2020). The potential of measuring success rate for archaeological science may be illustrated by an example, such as the production of Palaeolithic birch tar. We know several birch tar remains made by Neanderthals (Mazza et al., 2006; Grünberg et al., 1999; Niekus et al., 2019) but up until today, it remains totally unknown with which technique the tars were made. This question can most likely be answered by chemical analysis of the known artefacts (for a possible methodology see: Rageot et al., 2019). In this way, it can be decided whether Palaeolithic birch tar production included indirect heating underground (hidden from the sight of 
an observer) or whether it did not, e.g., being an above-ground open-air process (compare: Kozowyk et al., 2017; Schmidt et al., 2019a). In a second step, the success rate of the found technique can be investigated experimentally by experts that are skilled in making birch tar and learners. These data can be compared with published success rate data of experts and learners in other techniques (e.g., for stone knapping, see: Bril et al., 2010) or with similar experiments conducted by the same experimenters. If several different birch tar production techniques can be identified based on the known artefacts, success rate can be compared between them. Such an approach gives insight into the need for high fidelity copying for executing these techniques and, thus, the cognitive effort required for their learning and execution.

[3] It appears that even the historical differences between the Wellington and the steak may find their analogue in archaeological science-raising a point that is somehow related to hypothesis 2 . This means that some techniques may be more (technologically) evolved than others. Tomasello (2009) proposes that the evolution of cumulative culture is based on a ratcheting effect (i.e., one trait builds upon the other). In this sense, cumulative culture is likely unique to humans (Tennie et al., 2009). It has even been proposed (Tennie et al., 2016) that many Stone age techniques do not pinpoint the presence or absence of cumulative culture in some of the older archaeological contexts like the Oldowan (for an alternative view, see: Haidle and Schlaudt, 2020). While this proposition was not meant, and is likely not useful, to help our understanding of the contexts that yielded the transformative techniques discussed in this paper (i.e., postdating $200 \mathrm{ka}$ ), it nonetheless raises another important question. Can we test for different degrees of the mechanisms underlying cumulative culture through archaeological observation? In other words, do different techniques rely more on a ratcheting effect than others? In the case of Stone Age transformative techniques, this question can be investigated by gathering data on whether techniques can be discovered randomly or whether they were more likely cultural evolutions (at least in parts) of previous techniques, i.e., ratcheting. For example, if it will be found that intentionally reddened ochre, as it was found at Fumane Cave in Italy (Cavallo et al., 2018) relied on heat treatment using open-air fires, it may be concluded that such a technique can be the result of a random discovery. It is easy to imagine that ochre fell in a fire at one point in the history of the cave and that the colour change of the ochre was noticed subsequently. If, on the other hand, ochre was and had to be slowly heated underground (as proposed for some contexts, e.g., Wadley, 2013), a process that is much less likely to be discovered fortuitously, it may be argued that this process represents a later step, i.e., the technical evolution of another, perhaps simpler, technique. In the latter case, ochre heat treatment can be considered a technical evolution that must be invented on purpose.

These three ways to compare different techniques are based on criteria that can be either measured in artefacts or investigated by experimentation. They build a theoretical framework and provide an alternative to the often-used concept of complexity (compare Langley et al., 2008; Niekus et al., 2019; Kozowyk et al., 2017; Kuhn and Hovers, 2013). Complexity theory in Archaeology normally refers to larger patterns such as whole societies and their evolution (Bentley and Maschner, 2007). Some authors (e.g., Wengrow and Graeber, 2015; McNiven, 2019) strongly argue against a distinction between 'complex' and 'simple' when applying the notion of complexity to the study of ancient societies because it may entail colonial attitudes to ideas around ancient technology. In a narrower sense, the notion of complex behaviours has been used to understand isolated Stone Age techniques (see among others: Langley et al., 2008; Niekus et al., 2019). In this sense, the notion is often used to refer to something complicated (i.e., including many working parts) rather than complex (i.e., having deterministic but unpredictable behaviour). Originally, the concept was used for understanding the production of personal ornaments (White, 1989) or stone tools (Roche and Texier, 1991) quantitatively. More recently, complexity has been used to signal the presence of traits indicating behavioural modernity (e.g., Dayet et al., 2017; Wadley et al., 2009; Shea and Sisk, 2010). Indeed, some authors call archaeological behaviours complex if they involve specific artefacts, such as compound adhesives (as in Wadley, 2010b) or stone-tipped spears (as in Ambrose, 2001). There is often no quantitative definition of complexity that would allow for comparing different behaviours (Perreault et al., 2013), so that the term effectively becomes a synonym of modernity. Other Authors (e.g., Milks, 2020) advise to be cautious when using the notion of complexity (as opposed to simplicity) because of the often made association of complexity and cognitive abilities of past populations. There are, however, a few approaches that aim at using complexity as a purely quantitative measure. In these works, complexity is often understood as the total amount of steps needed to conduct a task (Bettinger and Eerkens, 1997) or it might be approached through the length of a problem-solution distance (Köhler, 1963; Haidle, 2014). While no uniquely accepted definition of complexity is used across a larger corpus of works, the number of steps performed during a technique or behaviour appears to be a concept common to most approaches (although steps may be called differently: phases; procedural units; etc., see for ex: Perreault et al., 2013; Haidle, 2014). In the case of stone tool knapping, such approaches based on the number of steps, may allow to make quantitative statements on production processes because most performed steps leave traces that can be read though technological analysis (Perreault et al., 2013). In the case of transformative techniques, however, a major problem arises: most performed steps do not leave traces in the artefacts found by archaeologists. As illustrated by the steak vs. beef Wellington analogy above, it is not straightforward to test assumptions on the number of steps performed. Even with approaches that aim at identifying the minimum number of steps needed (i.e., the easiest way of doing something), it cannot be tested whether interpretations correspond to reality. Stone Age techniques may have been executed with more steps 'than necessary' (if they were embedded in another technique or a ritual, etc.). Alternatively, techniques may have been executed with less steps than expected (if a modern-day analyst did not identify the easiest way to perform the task). Even future developments of new ways to analyse and interpret steps (computeraided graphical or logical interpretations of processes, analysis of algorithms, cognitive task analysis,etc.; for some of these concepts see: Clark et al., 2007; Dechter, 2003) will be based on the same assumption (that there were so many of steps and what these steps were), the correctness of which cannot be verified.

Thus, the accuracy of any interpretation based on the steps of a procedure cannot be properly tested for, in other words there is no mechanism that would allow to ascertain that the choice of steps reflects reality. On the other hand, the three approaches outlined above - comparing i) the requirement in time and/or raw materials, ii) the difficulty of a technique and iii) the possibility to discover the technique randomly - are based on testable criteria.

\section{Predictions made for early fire-based transformative techniques}

Three hypotheses can be formulated from this. The order of the latter two arguments discussed above is inversed in these hypotheses. If they are supported by experimental and archaeological data in the future, Stone Age transformative techniques may be regarded as more meaningful for our understanding of human evolution than other contemporaneous techniques. 
Hypothesis [1]: (Some) transformative techniques require greater investment in time and resources than other contemporaneous techniques. If hypothesis 1 will find support, its implications are that the objects produced by these techniques were potentially of higher value than other objects. Understanding required investment does not necessarily require a complete understanding of the processes actually used in the Stone Sage. The test conditions for this are as follows:

Different techniques are reproduced experimentally or in laboratory conditions. This allows for understanding reaction kinetics of the processes.

Raw material requirement is investigated by chemical analysis of the artefacts (i.e., how many raw materials are observed to form part of an artefact, e.g., in a composite adhesive?).

Results are compared between different techniques from within specific archaeological contexts (i.e., one transformative technique vs. another and vs. other nontransformative techniques).

Finding that (some) transformative techniques are more time and resource demanding than other techniques (i.e., more costly) would provide a first argument in favour of their importance for human evolution.

Hypothesis [2]: (Some) transformative techniques reflect a higher degree of technical evolution than other contemporaneous techniques. Unlike for hypothesis 1, investigating hypothesis 2 requires an understanding of the pathways actually used for conducting techniques in the Stone Age. The test conditions are as follows:

- Different techniques are reproduced experimentally in different ways to obtain reference samples.

Proxies that pinpoint specific transformation pathways are identified in these reference samples (proxies are likely quantities measurable by chemistry and material science).

- These proxies are compared in experimental reference samples and artefacts to identify which transformation pathway was used in the Stone Age.

- This, in turn, allows to identify whether the pathway includes processes that can accidentally be triggered (i.e., without the intent to perform a transformative technique) or whether they must be invented.

If the technique can be discovered randomly, it cannot be argued to reflect cumulative culture. If the technique includes processes that cannot be discovered randomly, i.e., that must be derived or improved from other known processes, it may be argued to document the ratcheting effect (Tomasello, 2009) associated with cumulative culture. Thus, if hypothesis 2 will find support, it may be argued that some fire-based transformative techniques required a higher degree of cultural transmission than other techniques.

Hypothesis [3]: Fire-based transformative techniques (perhaps only those that include invisible processes) require higher fidelity copying than other techniques (and those transformative techniques that do not include invisible processes). From answering hypothesis 2, it will be known which techniques include invisible processes. The test conditions for hypothesis 3 are therefore as follows:

Different techniques are conducted by learners and experts (these are experimenters that will have acquired skill in performing the techniques). Several experimental runs are repeated for a statistically significant number of times.

- The data provided by these tests reflect success rate (including as a function of the presence or absence of invisible processes). These data can be analysed in terms of the need, or not, of high fidelity copying.
If this hypothesis will be supported by experimental and archaeological data, its implications are that some techniques, e.g., those that include hidden processes, in other words that contain elements that cannot be understood (Csibra and Gergely, 2011), are more difficult, i.e. demand more effort to be carried out successfully, than other non-transformative techniques. They could be understood to require higher fidelity copying than other contemporaneous techniques.

\section{An example of a potential application: birch tar from the European Middle Palaeolithic}

As outlined above, the technique Neanderthals used to make birch tar in unknown. Hypotheses include underground processed that cannot be observed (Kozowyk et al., 2017) but also fully visible open-air processes (Schmidt et al., 2019a). For now, the only available information that can be analysed in terms of the three predictions outlined above is the composition of some of the known birch tar artefacts (Niekus et al., 2019). CT-scans of the Zandmotor artefact document traces of charcoal and potentially sediment (both may result from the production process) but no deliberate mixing of ingredients. Thus, from the point of view of observable ingredients, the tar artefact appears to be comparable with common contemporaneous artefacts where only few raw materials were used. The reaction kinetics of tar formation from birch bark have recently been found to be rather fast. 15 min of heating the bark produces the amount of tar that can be produced at a given heating temperature (Koch and Schmidt, 2021). This minimal time requirement seems to be in agreement with the time requirement for contemporaneous non-transformative techniques (like stone knapping for example). Thus, hypothesis 1 (that Middle Palaeolithic birch tar demanded more investment per se than other contemporaneous techniques) is not supported by the available direct archaeological data because only a single raw material is actually documented (birch bark) and the measurable reaction kinetics of tar formation are short. It might be (rightly) argued that supplementary raw materials must have been involved in tar making and that the whole process must have taken more time than the measurable reaction kinetics but without the knowledge of which technique was used, the number of raw materials and the duration of the procedure are speculative. And indeed, it has been found that usable amounts of birch tar can be made in rather short time periods and using only few raw materials (Blessing and Schmidt, 2021). What about hypothesis 2 , that the known birch tar artefacts document a higher degree of technological evolution than other contemporaneous artefacts? For now, this hypothesis cannot be answered based on the available data, but the experimental programme necessary to either support or refute it is obvious: A reference collection containing birch tar samples made with different aceramic techniques must be built. Analysing these samples in terms of their chemistry (e.g., Rageot et al., 2019) should allow to pinpoint chemical markers of different formation environments (e.g., oxygen-depleted underground vs. fully oxygenated above-ground). If these markers can be identified in one or more of the known birch tar artefacts, it will be known whether Neanderthals distilled tar from bark in a hidden invisible environment or above-ground in plain sight. In the former case, birch tar can be understood to document a high degree of cumulative culture involved in Neanderthal technology because it is unlikely that an invisible underground process was invented ex nihilo (in other words, there must have been a another process that can be discovered randomly and on which the observed technique is based). In the latter case, birch tar making cannot be understood as a proxy for cultural transmission or cumulative culture. The formation of birch tar might have been discovered accidentally and there would be no indication that the initial discovery was altered through passing it on culturally (in other words, Neanderthals might 
have discovered the technique several times independently instead of maintaining it as a lasting cultural tradition). Today, there are no data to support or refute the hypothesis that birch tar documents a higher degree of cumulative culture than other non-transformative Neanderthal techniques (n.b. it is not suggested here that birch tar making alone can resolve the question whether Neanderthal technology relied on cumulative culture or not; investigating hypothesis 2 is intended to help understand the role of transformative technologies as opposed to other techniques). The third hypothesis, that birch tar making was more difficult than other contemporaneous techniques, cannot be evaluated yet either. There are some data on success rate of different aceramic birch tar making techniques, suggesting that some techniques relying on invisible processes fail more often than fully visible procedures (e.g., Kozowyk et al., 2017; Schenck and Groom, 2018; Blessing and Schmidt, 2021). Whether one of these techniques was actually used in the Middle Palaeolithic remains unknown. If some aspects of the chemical and physical processes involved in the actually used Stone Age techniques can be identified (allothermic vs autothermic, with separation or without, condensation or dripping, for these concepts see: Kurzweil and Todtenhaupt, 1992; Rageot et al., 2019; Schmidt et al., 2019a), it will be possible to evaluate the success rate associated with different aceramic techniques that contain such processes through an experimental programme. Such success rate data can be compared with the success rate of non-transformative techniques to understand whether birch tar making was more difficult than other contemporaneous technologies. The implications would be that tar making relied more on high fidelity copying than other technologies.

Investigating these three hypotheses constitutes a means of comparing birch tar making with other Neanderthal techniques. The projected outcome may appear less spectacular than discussions on Neanderthal complex behaviours but the approach leaves less room to arbitrariness. Should future data support hypotheses 2 and 3, it may be argued that Middle Palaeolithic birch tar is a stronger proxy for the reliance of Neanderthal technology on cumulative culture and for social mechanisms that enable high fidelity copying, than other contemporaneous artefacts.

\section{Conclusion}

This paper identifies three ways to interpret early transformative techniques. These three aspects may appear to be limited in comparison with broader discussion on the advent of modern behaviours or the cognitive evolution of early humans, but they constitute a basis for future, perhaps more philosophical, discussions on the meaning of transformative technologies, allowing them to be rooted in testable data. Three questions can be asked for this: how investment-intensive were fire-based transformative techniques relative to other techniques? How difficult were they relative to other techniques? Must they be evolved from other pre-existing techniques? Quantifying complexity, in terms of required or preformed steps, is less promising for comparing techniques because the correctness of the underlying assumptions cannot be verified through measurements or experimentation. The test conditions for supporting or refuting the three hypotheses are relatively straightforward in terms of methodology. However, investigating these hypotheses relies on a large corpus of knowledge that is currently unavailable for most transformative techniques in most archaeological contexts. Such knowledge on the chemical and physical pathways associated with transformative techniques must be produced by future studies. The most promising approach for future studies is the combination of experimentation, chemical or physical analysis of experimentally produced reference objects and the comparison of experimental samples and archaeological artefacts. The results might allow a better understanding of early transformative techniques in an evolutionary model.

\section{Data availability}

Data sharing not applicable to this article as no datasets were generated or analysed during the current study.

Received: 5 July 2021; Accepted: 2 November 2021; Published online: 18 November 2021

\section{References}

Ambrose SH (2001) Paleolithic technology and human evolution. Science 291(5509):1748. https://doi.org/10.1126/science.1059487

Aubry T, Bradley B, Almeida M, Walter B, Joao Neves M, Pelegrin J, Tiffagom ML (2008) Solutrean laurel leaf production at Maîtreaux: an experimental approach guided by techno-economic analysis. World Archaeol 40(1):48-66 Bandura A (1997) Social learning theory. Englewood Cliffs, New Jersey

Bar-Yosef O (1998) On the nature of transitions: the middle to upper palaeolithic and the neolithic revolution. Camb Archaeol J 8(2):141-163. https://doi.org/ 10.1017/S0959774300001815

Bentley RA, Maschner HDG (2007) Complexity theory. In: Bentley RA, Maschner HDG, Chippendale C (eds) Handbook of archaeological theories. AltaMira Press, Maryland, p 245-270

Bettinger RL, Eerkens J (1997) Evolutionary implications of metrical variation in Great Basin projectile points. In: Barton CM, Clark GA (eds) Rediscovering Darwin: evolutionary theory and archaeological explanation. archaeological papers No. 7. American Anthropological Association, Arlington, pp. 177-191

Blessing M, Schmidt P (2021) On the efficiency of Palaeolithic birch tar making. J Archaeol Sci 38:103096

Bordes F (1969) Traitement thermique du silex au Solutréen. Bulletin de la Société préhistorique française 66(7):197

Bril B, Rein R, Nonaka T, Wenban-Smith F, Dietrich G (2010) The role of expertise in tool use: skill differences in functional action adaptations to task constraints. J Exp Psychol Hum Percept Perform 36(4):825-839. https://doi.org/ $10.1037 / \mathrm{a} 0018171$

Brown K, Marean C (2010) Wood fuel availability for heat treatment drives the rise and fall of silcrete as a raw material in the middle stone age of south africa, "abstracts of the paleoanthropology society 2010 meetings.". PaleoAnthropology 2010:A0001-A0040

Brown KS, Marean CW, Herries AIR, Jacobs Z, Tribolo C, Braun D, Roberts DL, Meyer MC, Bernatchez J (2009) Fire as an engineering tool of early modern Humans. Science 325(5942):859-862

Canteloup C, Hoppitt W, van de Waal E (2020) Wild primates copy higher-ranked individuals in a social transmission experiment. Nat Commun 11(1):459. https://doi.org/10.1038/s41467-019-14209-8

Cavallo G, Fontana F, Gialanella S, Gonzato F, Riccardi MP, Zorzin R, Peresani M (2018) Heat treatment of mineral pigment during the upper palaeolithic in north-east Italy. Archaeometry 60(5):1045-1061. https://doi.org/10.1111/ arcm. 12360

Charrié-Duhaut A, Porraz G, Cartwright C, De Araujo M, Conan J, Poggenpoel C, Texier P-J (2013) First molecular identification of a hafting adhesive in the Late Howiesons Poort at Diepkloof Rock Shelter, Western Cape, South Africa. J Archaeol Sci 40(9):3506-3518

Clark RE, Feldon D, vanMerrienboer J, Yates K, Early S (2007) Cognitive Task Analysis. In: J. M. M, D. M, van Merriënboer J, Driscoll MP (eds) Handbook of research on educational communications and technology. NJ: Lawrence Erlbaum Associates, Mahwah

Csibra G, Gergely G (2011) Natural pedagogy as evolutionary adaptation. Philos Trans R Soc Lond B Biol Sci 366(1567):1149-1157. https://doi.org/10.1098/ rstb.2010.0319

D'Errico F (2003) The invisible frontier. A multiple species model for the origin of behavioral modernity. Evol Anthropol 12(4):188-202. https://doi.org/ 10.1002/evan.10113

d'Errico F, Henshilwood C, Vanhaeren M, van Niekerk K (2005) Nassarius kraussianus shell beads from Blombos Cave: evidence for symbolic behaviour in the Middle Stone Age. J Human Evol 48(1):3-24

Dayet L, Texier PJ, Daniel F, Porraz G (2013) Ochre resources from the Middle Stone Age sequence of Diepkloof Rock Shelter, Western Cape, South Africa. J Archaeol Sci 40(9):3492-3505

Dayet L, Wurz S, Daniel F (2017) Ochre Resources, Behavioural Complexity and Regional Patterns in the Howiesons Poort. J Afr Archaeol 15(1):20-41

Dechter R (2003) chapter 1 - Introduction. In: Dechter R (ed) Constraint Processing. Morgan Kaufmann, San Francisco, pp. 1-22 
Degano I, Soriano S, Villa P, Pollarolo L, Lucejko JJ, Jacobs Z, Douka K, Vitagliano S, Tozzi C (2019) Hafting of Middle Paleolithic tools in Latium (central Italy): New data from Fossellone and Sant'Agostino caves. PLoS ONE 14(6):e0213473

Delagnes A, Schmidt P, Douze K, Wurz S, Bellot-Gurlet L, Conard NJ, Nickel KG, van Niekerk KL, Henshilwood CS (2016) Early Evidence for the Extensive Heat Treatment of Silcrete in the Howiesons Poort at Klipdrift Shelter (Layer PBD, $65 \mathrm{ka}$ ), South Africa. PLoS ONE 11(10):e0163874. https://doi.org/ 10.1371/journal.pone.0163874

Eriksen BV (1997) Implications of thermal pre-treatment of chert in the German Mesolithic. In: Schild R, Sulgostowska Z (eds) Man and Flint, Proceedings of the VII International Flint Symposium Warszawa-Ostrowiec Swietokrzyski, September 1995. Institute of Archaeology and Ethnology Polish Academy of Sciences, Warsaw, pp. 325-329

Flenniken J (1987) The paleolithic dyuktai pressure blade technique of Siberia. J Arctic Anthropol 24:117-132

Godfrey-Smith DI, Ilani S (2004) Past thermal history of goethite and hematite fragments from Qafzeh Cave deduced from thermal activation characteristics of the $110^{\circ} \mathrm{C}$ TL peak of enclosed quartz grains. ArchéoSciences, revue d'Archéométrie 28:185-190

Gould RA, Saggers S (1985) Lithic procurement in central Australia: a closer look at Binford's idea of embeddedness in archaeology. Am Antiq 50(1):117-136. https://doi.org/10.2307/280637

Groom P, Schenck T, Pedersen GM (2015) Experimental explorations into the aceramic dry distillation of Betula pubescens (downy birch) bark tar. Archaeol Anthropol Sci 7(1):47-58. https://doi.org/10.1007/s12520-013-0144-5

Grünberg J, Gratsch H, Baumer U, Koller J (1999) Utersuchung der mittelpaläolithischen "Harzreste" von Königsaue, Ldkr. Aschersleben-Stassfurt. Jahresschrift für mitteldeutsche Vorgeschichte 81:7-38

Haidle MN (2014) Building a bridge-an archeologist's perspective on the evolution of causal cognition. Front Psychol 5:1472. https://doi.org/10.3389/ fpsyg.2014.01472

Haidle MN, Schlaudt O (2020) Where does cumulative culture begin? a plea for a sociologically informed perspective. Biol Theory 15(3):161-174. https:// doi.org/10.1007/s13752-020-00351-w

Harmand S, Lewis JE, Feibel CS, Lepre CJ, Prat S, Lenoble A, Boës X, Quinn RL, Brenet M, Arroyo A, Taylor N, Clément S, Daver G, Brugal J-P, Leakey L, Mortlock RA, Wright JD, Lokorodi S, Kirwa C, Kent DV, Roche H (2015) 3.3-million-year-old stone tools from Lomekwi 3, West Turkana, Kenya. Nature 521(7552):310-315. https://doi.org/10.1038/nature14464

Henry AG (2017) Neanderthal cooking and the costs of fire. Curr Anthropol 58(S16):S329-S336. https://doi.org/10.1086/692095

Henry AG, Büdel T, Bazin P-L (2018) Towards an understanding of the costs of fire. Quater Int 493:96-105. https://doi.org/10.1016/j.quaint.2018.06.037

Henshilwood CS, d'Errico F, Watts I (2009) Engraved ochres from the Middle Stone Age levels at Blombos Cave, South Africa. J Human Evol 57(1):27-47

Hodgskiss T (2020) Ochre use in the middle stone age. In: Oxford Research Encyclopedia of Anthropology. Oxford University Press. https://doi.org/ 10.1093/acrefore/9780190854584.013.51

Klein R (1995) Anatomy, behavior, and modern human origins. J World Prehist 9(2):167-198. https://doi.org/10.1007/bf02221838

Koch TJ, Schmidt P (2021) The formation conditions of birch tar in oxygendepleted environments. Archaeol Anthropol Sci 13(6):92. https://doi.org/ 10.1007/s12520-021-01352-x

Köhler W (1963) Intelligenzprüfungen an Menschenaffen. Springer-Verlag, Berlin

Koller J, Baumer U, Mania D (2001) High-tech in the middle Palaeolithic: Neandertal-manufactured pitch identified. Eur J Archaeol 4(3):385-397. https://doi.org/10.1179/eja.2001.4.3.385

Kozowyk PRB, Soressi M, Pomstra D, Langejans GHJ (2017) Experimental methods for the Palaeolithic dry distillation of birch bark: implications for the origin and development of Neandertal adhesive technology. Sci Rep 7(1):8033. https://doi.org/10.1038/s41598-017-08106-7

Kuhn SL, Hovers E (2013) Alternative pathways to complexity: evolutionary trajectories in the middle paleolithic and middle stone age: an introduction to supplement 8. Curr Anthropol 54(S8):S176-S182. https://doi.org/10.1086/ 673501

Kurzweil A, Todtenhaupt D (1992) Technologie der Holzteergewinnung. Acta Praehistorica et Archaeologica 23:63-91

Langley MC, Clarkson C, Ulm S (2008) Behavioural complexity in eurasian neanderthal populations: a chronological examination of the archaeological evidence. Camb Archaeol J 18(3):289-307. https://doi.org/10.1017/ S0959774308000371

Lewis HM, Laland KN (2012) Transmission fidelity is the key to the build-up of cumulative culture. Philos Trans R Soc Lond B Biol Sci 367(1599):2171-2180. https://doi.org/10.1098/rstb.2012.0119

Lombard M (2007) The gripping nature of ochre: the association of ochre with Howiesons Poort adhesives and Later Stone Age mastics from South Africa. J Human Evol 53(4):406-419. https://doi.org/10.1016/j.jhevol.2007.05.004
Lombard M, Parsons I (2011) What happened to the human mind after the Howiesons Poort? Antiquity 85(330):1433-1443. https://doi.org/10.1017/ S0003598X00062153

Malafouris L (2010) Metaplasticity and the human becoming: principles of neuroarchaeology. J Anthropol Sci 88:49-72

Mazza PPA, Martini F, Sala B, Magi M, Colombini MP, Giachi G, Landucci F, Lemorini C, Modugno F, Ribechini E (2006) A new Palaeolithic discovery: tar-hafted stone tools in a European Mid-Pleistocene bone-bearing bed. J Archaeol Sci 33(9):1310-1318. https://doi.org/10.1016/j.jas.2006.01.006

McBrearty S, Brooks AS (2000) The revolution that wasn't: a new interpretation of the origin of modern human behavior. J Human Evol 39(5):453-563

McNiven I (2019) Primordialising Aboriginal Australians. In: Porr M, Matthews I (eds) Interrogating Human Origins. Colonialist tropes and Eurocentric views on behavioural markers of modern humans. Routledge, London, pp. 96-111

Mellars PA, Stringer CB (1989) The Human Revolution: Behavioral and Biological Perspectives on the Origins of Modern Humans. Edinburgh University Press, Edinburgh

Milks A (2020) A review of ethnographic use of wooden spears and implications for pleistocene hominin hunting. Open Quaternary 6(1):12

Niekus MJLT, Kozowyk PRB, Langejans GHJ, Ngan-Tillard D, van Keulen H, van der Plicht J, Cohen KM, van Wingerden W, van Os B, Smit BI, Amkreutz LWSW, Johansen L, Verbaas A, Dusseldorp GL (2019) Middle Paleolithic complex technology and a Neandertal tar-backed tool from the Dutch North Sea. Proc. Natl Acad. Sci. 201907828. https://doi.org/10.1073/pnas.1907828116

Noble W, Davidson I (1991) The evolutionary emergence of modern human behaviour: language and its archaeology. Man 26(2):223-253. https://doi.org/ $10.2307 / 2803830$

Pawlik A, Thissen J (2011) Hafted armatures and multi-component tool design at the Micoquian site of Inden-Altdorf, Germany. J Archaeol Sci 38:1699-1708

Perreault C, Brantingham PJ, Kuhn SL, Wurz S, Gao X (2013) Measuring the Complexity of Lithic Technology. Curr Anthropol 54(S8):S397-S406. https:// doi.org/10.1086/673264

Petraglia MD, Haslam M, Fuller DQ, Boivin N, Clarkson C (2010) Out of Africa: new hypotheses and evidence for the dispersal of Homo sapiens along the Indian Ocean rim. Ann Human Biol 37(3):288-311. https://doi.org/10.3109/ 03014461003639249

Porraz G, Igreja M, Schmidt P, Parkington JE (2016) A shape to the microlithic Robberg from Elands Bay Cave (South Africa). South Afr Human 29:203-247

Rageot M, Théry-Parisot I, Beyries S, Lepère C, Carré A, Mazuy A, Filippi J-J, Fernandez X, Binder D, Regert M (2019) Birch Bark Tar Production: Experimental and Biomolecular Approaches to the Study of a Common and Widely Used Prehistoric Adhesive. J Archaeol Method Theor 26(1):276-312. https://doi.org/10.1007/s10816-018-9372-4

Roche H, Texier P-J (1991) La notion de complexite dans un ensemble lithique. In: 25 ans d'études technologiques en préhistoire. Xe Rencontre Internationales d'Archéologie et d'Histoire Antibes. APDCA, Antibes, pp 99-108

Rots V, Van Peer P, Vermeersch PM (2011) Aspects of tool production, use, and hafting in Palaeolithic assemblages from Northeast Africa. J Human Evol 60(5):637-664. https://doi.org/10.1016/j.jhevol.2011.01.001

Saldana C, Fagot J, Kirby S, Smith K, Claidière N (2019) High-fidelity copying is not necessarily the key to cumulative cultural evolution: a study in monkeys and children. Proc R Soc B: Biol Sci 286(1904):20190729. https://doi.org/ 10.1098/rspb.2019.0729

Salomon, V C, Aubry T, Walter B, Vialou D, Menu M, Geneste J-M (2013) Les matières colorantes en contexte Solutréen: Combe Saunière (Dordogne), Fressignes (Indre) et Les Maîtreaux (Indre-et-Loire). In: Actes du Colloque: Le Solutréen... 40 ans après la publication du Smith'66, 21-10-2007 to 01-012007 in Preuilly-sur-Claise. pp. 319-330

Salomon H, Vignaud C, Coquinot Y, Beck L, Stringer C, Strivay D, D’Errico F (2012) Selection and heating of colouring materials in the mousterian Level Of Es-Skhul (C. 100000 Years Bp, Mount Carmel, Israel). Archaeometry 54(4):698-722. https://doi.org/10.1111/j.1475-4754.2011.00649.x

Salomon H, Vignaud C, Lahlil S, Menguy N (2015) Solutrean and Magdalenian ferruginous rocks heat-treatment: accidental and/or deliberate action? J Archaeol Sci 55:100-112. https://doi.org/10.1016/j.jas.2014.12.024

Schenck T, Groom P (2018) The aceramic production of Betula pubescens (downy birch) bark tar using simple raised structures. A viable Neanderthal technique? Archaeol Anthropol Sci 10(1):19-29. https://doi.org/10.1007/s12520016-0327-y

Schmidt P (2014) What causes failure (overheating) during lithic heat treatment? Archaeol Anthropol Sci 6(2):107-112

Schmidt P, Blessing M, Rageot M, Iovita R, Pfleging J, Nickel KG, Righetti L, Tennie C (2019a) Birch tar production does not prove Neanderthal behavioral complexity. Proc Natl Acad Sci 116(36):17707. https://doi.org/10.1073/ pnas.1911137116

Schmidt P, Buck G, Berthold C, Lauer C, Nickel K (2019b) The mechanical properties of heat-treated rocks: a comparison between chert and silcrete. Archaeol Anthropol Sci 11(6):2489-2506 
Schmidt P, February E, Bretzke K, Bellot-Gurlet L (2016a) Tempering-residue on heat-treated silcrete: an experimental perspective and a potential analytical protocol. J Archaeol Sci: Rep 15:611-619

Schmidt P, Hiscock P (2020a) The antiquity of Australian silcrete heat treatment: Lake Mungo and the Willandra Lakes. J Human Evol 142:102744

Schmidt P, Hiscock P (2020b) Early silcrete heat treatment in Central Australia: Puritjarra and Kulpi Mara. Archaeol Anthropol Sci 12(8):188. https://doi.org/ 10.1007/s12520-020-01163-6

Schmidt P, Lauer C, Buck G, Miller CE, Nickel KG (2017) Detailed near-infrared study of the 'water'-related transformations in silcrete upon heat treatment. Phys Chem Miner 44(1):21-31. https://doi.org/10.1007/s00269-016-0833-6

Schmidt P, Mackay A (2016) Why was silcrete heat-treated in the middle stone age? an early transformative technology in the context of raw material use at Mertenhof Rock Shelter, South Africa. PLoS ONE 11(2):e0149243. https:// doi.org/10.1371/journal.pone. 0149243

Schmidt P, Morala A (2018) First insights into the technique used for heat treatment of chert at the Solutrean site of Laugerie-Haute, France. Archaeometry 60(5):885-897

Schmidt P, Morala A (2020) Are we missing out on half of all heat-treated pieces in the solutrean? Lithic Technol 45(1):48-58. https://doi.org/10.1080/ 01977261.2019 .1695076

Schmidt P, Paris C, Bellot-Gurlet L (2016b) The investment in time needed for heat treatment of flint and chert. Archaeol Anthropol Sci 8(4):839-848

Schmidt P, Porraz G, Bellot-Gurlet L, February E, Ligouis B, Paris C, Texier JP, Parkington JE, Miller CE, Nickel KG, Conard NJ (2015) A previously undescribed organic residue sheds light on heat treatment in the Middle Stone Age. J Human Evol 85:22-34

Schmidt P, Porraz G, Slodczyk A, Bellot-Gurlet L, Archer W, Miller CE (2013) Heat treatment in the South African Middle Stone Age: temperature induced transformations of silcrete and their technological implications. J Archaeol Sci 40(9):3519-3531

Schmidt P, Stynder D, Conard NJ, Parkington JE (2020) When was silcrete heat treatment invented in South Africa? Palgrave Commun 6(1):73. https:// doi.org/10.1057/s41599-020-0454-z

Semaw S, Rogers MJ, Quade J, Renne PR, Butler RF, Dominguez-Rodrigo M, Stout D, Hart WS, Pickering T, Simpson SW (2003) 2.6-Million-year-old stone tools and associated bones from OGS-6 and OGS-7, Gona, Afar, Ethiopia. J Human Evol 45(2):169-177. https://doi.org/10.1016/S0047-2484(03)00093-9

Shea JJ (2011) Homo sapiens Is as Homo sapiens Was: Behavioral Variability versus "Behavioral Modernity" in Paleolithic Archaeology. Curr Anthropol 52(1):1-35

Shea JJ, Sisk ML (2010) Complex projectile technology and Homo sapiens dispersal into western Eurasia. PaleoAnthropology 2010:100-122

Stolarczyk RE, Schmidt P (2018) Is early silcrete heat treatment a new behavioural proxy in the Middle Stone Age? PLoS ONE 13(10):e0204705

Tennie C, Braun DR, Premo L, McPherron SP (2016) The Island test for cumulative culture in the Paleolithic. In: The nature of culture. Springer, pp. 121-133

Tennie C, Call J, Tomasello M (2009) Ratcheting up the ratchet: on the evolution of cumulative culture. Philos Trans R Soc B: Biol Sci 364(1528):2405-2415. https://doi.org/10.1098/rstb.2009.0052

Tennie C, Premo LS, Braun DR, McPherron SP (2017) Early stone tools and cultural transmission: resetting the null hypothesis. Curr Anthropol 58(5):652-672. https://doi.org/10.1086/693846

Tomasello M (2009) The cultural origins of human cognition. Harvard university press

Wadley L (2010a) Compound-adhesive manufacture as a behavioral proxy for complex cognition in the middle stone age. Curr Anthropol 51(S1):S111-S119. https://doi.org/10.1086/649836

Wadley L (2010b) Compound-adhesive manufacture as a behavioral proxy for complex cognition in the Middle Stone Age. Curr Anthropol 51(Supplement 1):111-119

Wadley L (2013) Recognizing complex cognition through innovative technology in stone age and palaeolithic sites. Camb Archaeol J 23(02):163-183

Wadley L, Hodgskiss T, Grant M (2009) Implications for complex cognition from the hafting of tools with compound adhesives in the Middle Stone Age, South Africa. Proceedings of the National Academy of Sciences 106(24):9590-9594

Wadley L, Prinsloo LC (2014) Experimental heat treatment of silcrete implies analogical reasoning in the Middle Stone Age. J Human Evol 70(0):49-60
Wengrow D, Graeber D (2015) Farewell to the 'childhood of man': ritual, seasonality, and the origins of inequality. J R Anthropol Inst 21(3):597-619. https://doi.org/10.1111/1467-9655.12247

White R (1989) Production Complexity and Standardization in Early Aurignacian Bead and Pendant Manufacture: Evolutionary Implications. In: Mellars P, Stringer C (eds) The human revolution: behavioral and biological perspectives on the origins of modern humans. Edinburgh University Press, Edinburgh, p 366-390

Whiten A (2011) The scope of culture in chimpanzees, humans and ancestral apes. Philos Transac R Soc B: Biol Sci 366(1567):997-1007. https://doi.org/10.1098/ rstb.2010.0334

Wojcieszak M, Hodgskiss T, Colomban P, Wadley L (2017) Finding Chemical and physical evidence of heat treatment of ochre by using non-destructive methods: a preliminary study. In: Pereira T, Terradas X, Bicho N (eds) Raw materials exploitation in prehistory: sourcing, processing and distribution. Cambridge Scholars Publishing, Cambridge, pp. 587-600

Zilhão J (2007) The emergence of ornaments and art: an archaeological perspective on the origins of "behavioral modernity". J Archaeol Res 15(1):1-54. https:// doi.org/10.1007/s10814-006-9008-1

\section{Acknowledgements}

Financial support was provided by the Deutsche Forschungsgemeinschaft (DFG) (grant number SCHM 3275/3-1). I also acknowledge support by Open Access Publishing Fund of University of Tübingen.

\section{Funding}

Open Access funding enabled and organized by Projekt DEAL.

\section{Competing interests}

The author declares no competing interests.

\section{Ethical approval}

This article does not contain any studies with human participants performed by any of the authors.

\section{Informed consent}

This article does not contain any studies with human participants performed by any of the authors.

\section{Additional information}

Correspondence and requests for materials should be addressed to Patrick Schmidt.

Reprints and permission information is available at http://www.nature.com/reprints

Publisher's note Springer Nature remains neutral with regard to jurisdictional claims in published maps and institutional affiliations.

Open Access This article is licensed under a Creative Commons Attribution 4.0 International License, which permits use, sharing, adaptation, distribution and reproduction in any medium or format, as long as you give appropriate credit to the original author(s) and the source, provide a link to the Creative Commons license, and indicate if changes were made. The images or other third party material in this article are included in the article's Creative Commons license, unless indicated otherwise in a credit line to the material. If material is not included in the article's Creative Commons license and your intended use is not permitted by statutory regulation or exceeds the permitted use, you will need to obtain permission directly from the copyright holder. To view a copy of this license, visit http://creativecommons.org/ licenses/by/4.0/.

(C) The Author(s) 2021 